Article

\title{
Hybrid Modulation of Bidirectional Three-Phase Dual-Active-Bridge DC Converters for Electric Vehicles
}

\author{
Yen-Ching Wang, Fu-Ming Ni and Tzung-Lin Lee * \\ Department of Electric Engineering, National Sun Yat-sen University, Kaohsiung 80424, Taiwan; \\ diodeathdeath@yahoo.com.tw (Y.-C.W.); joy19951231@hotmail.com (F.-M.N.) \\ * Correspondence: tllee@mail.ee.nsysu.edu.tw; Tel.: +886-7-525-2000 (ext. 4197) \\ Academic Editors: Frede Blaabjerg and Dirk Söffker \\ Received: 9 March 2016; Accepted: 23 June 2016; Published: 27 June 2016
}

\begin{abstract}
Bidirectional power converters for electric vehicles (EVs) have received much attention recently, due to either grid-supporting requirements or emergent power supplies. This paper proposes a hybrid modulation of the three-phase dual-active bridge (3ФDAB) converter for EV charging systems. The designed hybrid modulation allows the converter to switch its modulation between phase-shifted and trapezoidal modes to increase the conversion efficiency, even under light-load conditions. The mode transition is realized in a real-time manner according to the charging or discharging current. The operation principle of the converter is analyzed in different modes and thus design considerations of the modulation are derived. A lab-scaled prototype circuit with a $48 \mathrm{~V} / 20 \mathrm{Ah}$ $\mathrm{LiFePO}_{4}$ battery is established to validate the feasibility and effectiveness.
\end{abstract}

Keywords: $\mathrm{DAB} ; \mathrm{LiFePO}_{4}$ battery; EV charger

\section{Introduction}

Fossil-fuel shortages and environmental concerns have strongly impacted the energy industries during the last decades. As one of the promising solutions to reduce the usage of the fossil fuel and carbon emissions, electric vehicles (EVs) are receiving much attention. Various infrastructures and charging standards for EVs have been presented considering different power levels as well as charging fields [1]. Among them, the direct-current charging standard, which is defined to deliver high power and high current charging capability, normally requires an off-board charger. Traditionally, a unidirectional dc converter is able to satisfy the requirement of refreshing battery energy. Recently, various economical and technical issues about using EVs to support the power grid have been discussed [2,3]. In this sense, power has to be delivered between the utility and EVs to meet demand response and/or take advantage of time-of-use electricity rates. On the other hand, EVs should be able to act as a standalone backup power in emergency situations [4-6]. Regarded as distributed energy resources, in this scenario EVs require an interface dc converter with both charging and discharging capabilities.

The dual active bridge (DAB) dc converter is a widely used circuit topology intended for bidirectional power flow, due to its soft-switching characteristic, high efficiency and low volume [7]. The DAB converter is typically controlled by using so-called phase-shifted modulating method, in which two-level square waves with a designated phase shift are applied to the isolated transformer. In this sense, power flow and its direction can be controlled by the phase difference. However, this control method suffers from low conversion efficiency under light-load condition due to high conduction and switching losses. In order to improve the efficiency of the DAB converter, various modulating schemes have been presented. In $[8,9]$, one of voltage pulses across on the transformer was replaced by a three-level pulse. In this sense, the DAB converter can operate in a wide-range soft-switching mode and its conduction loss can also be reduced by considering the reactive power 
of the converter [10]. However, the required algorithm needs heavy computation to determine the operating point of the converter. The so-called triangular and trapezoidal modulations were proposed by imposing two three-level voltage pulses on the transformer [11,12]. By shaping the transformer current, both modulations can provide zero-current switching and reduce the circulating current under light-load conditions at the cost of voltage gain and power rating. Moreover, various optimization modulations have been proposed to reduce the peak current [10] or reactive power $[13,14]$, but they are not suitable for real-time applications due to their complexity.

In order for high-power applications, the bidirectional three-phase DAB (3ФDAB) converter has been presented [15]. The $3 \Phi D A B$ converter features higher power density compared with the single-phase $\mathrm{DAB}(1 \Phi \mathrm{DAB})$ converter. It is worth noting that the current frequency of the $3 \Phi \mathrm{DAB}$ converter is three times of that of the $1 \Phi \mathrm{DAB}$ converter. Thus the volume of the switching-ripple filters can be significantly reduced in the $3 \Phi D A B$ converter. However, similarly to $1 \Phi D A B$ converter, the $3 \Phi D A B$ converter with phase-shifted modulation still performs poor efficiency at low-power operation [16-21]. In [20], a hybrid modulation strategy was proposed for the $3 \Phi D A B$ converter, including phase-shifted, triangular and trapezoidal modulations. The converter is able to operate at the highest efficiency with a changeable modulating scheme according to the operating point. This study was focused on the estimations and analysis of the various modulations, but no information was provided on how to determine optimizing modulation, which may be very difficult in real-time implementation. Furthermore, the considered triangular modulation may substantially increase the complexity of the modulation scheme.

The authors have presented the $3 \Phi \mathrm{DAB}$ converter with hybrid modulation in previous research [21]. The converter is able to switch its modulation between phase-shifted and trapezoidal modes autonomously to maintain efficiency even in the light-load condition. In this paper, we further focused on theoretical analysis of the mode transition based on loss analysis of the circuit. The condition of when the modulation modes switch is pre-determined based on efficiency analysis. Design considerations of the modulation are also proposed and the corresponding suggested control progress with flowchart for hybrid modulation is also provided. A lab-scale platform consisting of a $1.2 \mathrm{~kW}$ $3 \Phi \mathrm{DAB}$ converter with a $48 \mathrm{~V} / 20 \mathrm{Ah} \mathrm{LiFePO}_{4}$ battery was established to verify the proposed method.

\section{Review of DAB Operation}

Figure 1 shows the $3 \Phi D A B$ converter. Two sets of three-phase half bridges are deployed with a three-phase isolated transformer. Various modulating strategies have been presented. The phase-shift modulation is able to provide zero-voltage switching (ZVS) for all switches, but this feature may lose in case of wide voltage gain and load variation. In order to assure ZVS in light load operation, the trapezoidal modulation was presented $[12,13,20,22]$. Here, we briefly review both modulations.

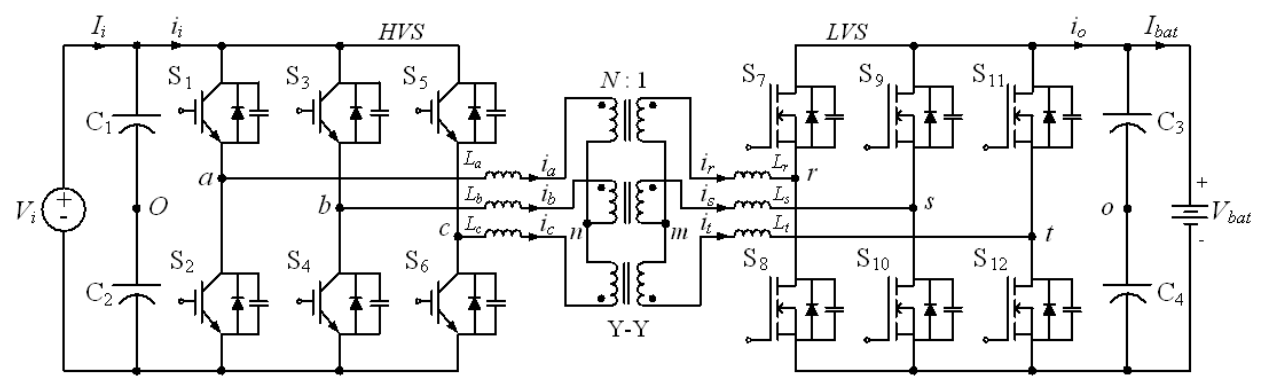

Figure 1. The bidirectional three-phase DAB DC/DC converter.

\section{1. $3 \Phi D A B$ Phase-Shift Modulation}

In phase-shift modulation, the switches in the primary-side legs are designed to operate at $50 \%$ duty ratio, while all three legs are with a $120^{\circ}$ phase shift among them. On the other hand, 
the secondary-side legs are controlled with designated phase shift with respect to the primary-side legs for proper power transfer between two dc sides. Figure 2a shows the theoretical waveforms of both phase voltages and phase current with phase-shift modulation. The $V_{a n}$ is a-phase voltage in the primary side and $V_{r m}$ ' is the secondary-side r-phase voltage $V_{r m}$ referred into primary-side. As can be seen, both phase voltages show a six-step square wave. The variable $i_{a}$ is the a-phase current that is determined according to voltage difference applied on the $L_{\text {eqa }}$, which is defined as the a-phase equivalent inductance referred to the primary side. In this case, $L_{\text {eqa }}$ is equal to $\left(L_{a}+N^{2} L_{r}\right)$. Thus the power transfer $P_{D}$ can be determined based on integrating both voltage and current. As shown in Equations (1) and (2), $P_{D}$ is dependent on the phase-shift angle $\delta$ between two sides of the transformer $[18,21]$ :

$$
\begin{gathered}
P_{D}=\frac{d V_{i}^{2}}{\omega L_{\text {eqa }}} \cdot\left(\frac{2 \delta}{3}-\frac{\delta^{2}}{2 \pi}\right), \text { for } 0 \leqslant \delta \leqslant \frac{\pi}{3} \\
P_{D}=\frac{d V_{i}^{2}}{\omega L_{\text {eqa }}} \cdot\left(\delta-\frac{\delta^{2}}{\pi}-\frac{\pi}{18}\right), \text { for } \frac{\pi}{3} \leqslant \delta \leqslant \frac{2 \pi}{3}
\end{gathered}
$$

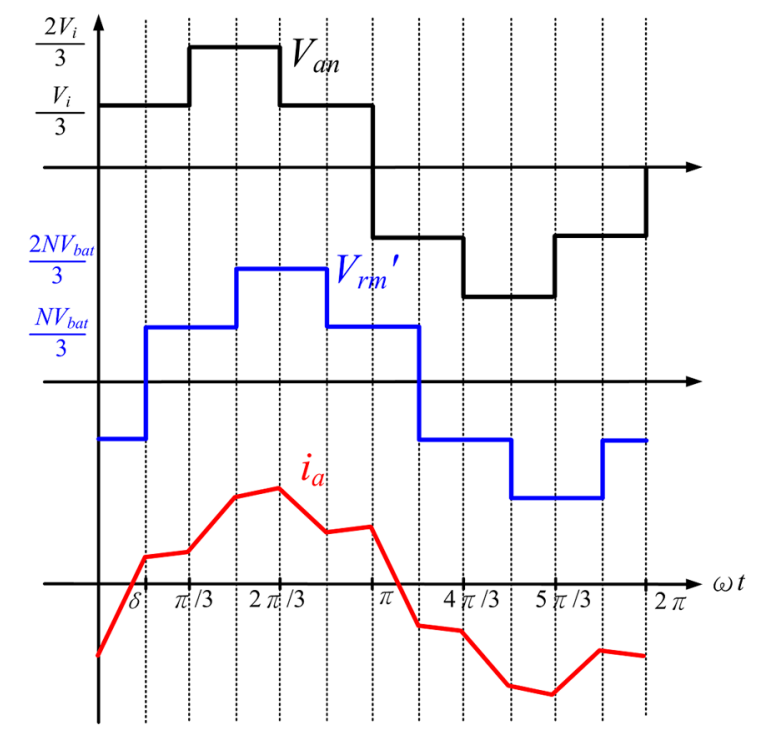

(a)

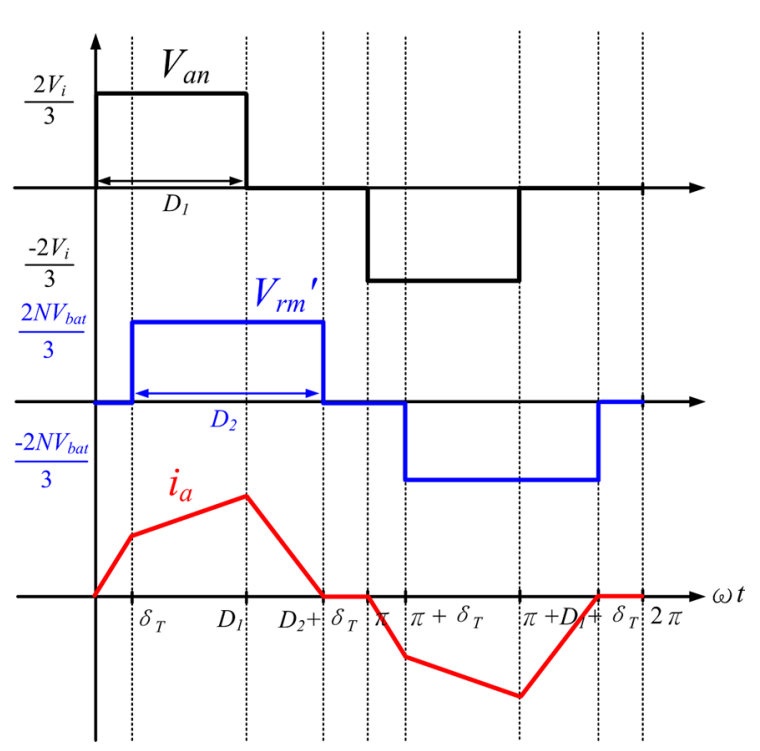

(b)

Figure 2. Theoretical waveforms of $3 \Phi \mathrm{DAB}$ converter. (a) Phase-shifted modulation; (b) Trapezoidal modulation.

The parameter $\mathrm{d}$ is defined as the voltage gain, equal to $\left(N V_{b a t} / V_{i}\right)$, and $\omega$ is the switching frequency in radians per second. The theoretical phase-shifted angle $\delta$ for a corresponding $P_{D}$ also can be expressed as the following Equations (3) and (4):

$$
\begin{gathered}
\delta=\frac{4 d \pi V_{i}^{2}-\sqrt{16 d^{2} \pi^{2} V_{i}^{4}-72 d \pi \omega L_{\text {eqa }} V_{i}^{2} P_{D}}}{6 d V_{i}^{2}}, \text { for } 0 \leqslant \delta \leqslant \frac{\pi}{3} \\
\delta=\frac{18 d \pi V_{i}^{2}-\sqrt{324 d^{2} \pi^{2} V_{i}^{2}-72 d^{2} \pi^{2} V_{i}^{4}-1296 d \pi \omega L_{\text {eqa }} V_{i}^{2} P_{D}}}{36 d V_{i}^{2}} \text {, for } \frac{\pi}{3} \leqslant \delta \leqslant \frac{2 \pi}{3}
\end{gathered}
$$

\section{2. $3 \Phi D A B$ Trapezoidal Modulation}

For $3 Ф D A B$ trapezoidal modulation, the two phases of the converter operate in parallel, which can be viewed as $1 \Phi \mathrm{DAB}$ trapezoidal modulation. Figure 3 shows the equivalent circuit. Since the b-phase 
and c-phase are in parallel, $L_{e q b}$ and $L_{e q c}$ are in parallel connection. Therefore, the total equivalent inductance $L_{e q T}$ can be expressed as Equation (5):

$$
L_{e q T}=L_{e q a}+L_{e q b, c}=1.5 \cdot L_{e q a}
$$

where $L_{e q b, c}$ is equal to $0.5 L_{\text {eqa }}$ assuming equal three-phase total equivalent inductances, $L_{e q a}, L_{e q b}$ and $L_{e q c}$. Figure $2 \mathrm{~b}$ shows the typical voltage and current waveforms of trapezoidal modulation. The power conversion $P_{T}$ can be expressed as Equations (6) and (7) [18,21]. Controllable variables include phase-shifted angle $\delta_{T}$, the primary- and secondary-side duty cycles $D_{1}, D_{2}$.

$$
\begin{gathered}
P_{T}=\frac{V_{i}^{2}}{2 \pi \omega L_{e q T}} \cdot\left[D_{1}^{2}-d\left(D_{1}-\delta_{T}\right)^{2}\right] \\
D_{2}=\frac{D_{1}}{d}
\end{gathered}
$$

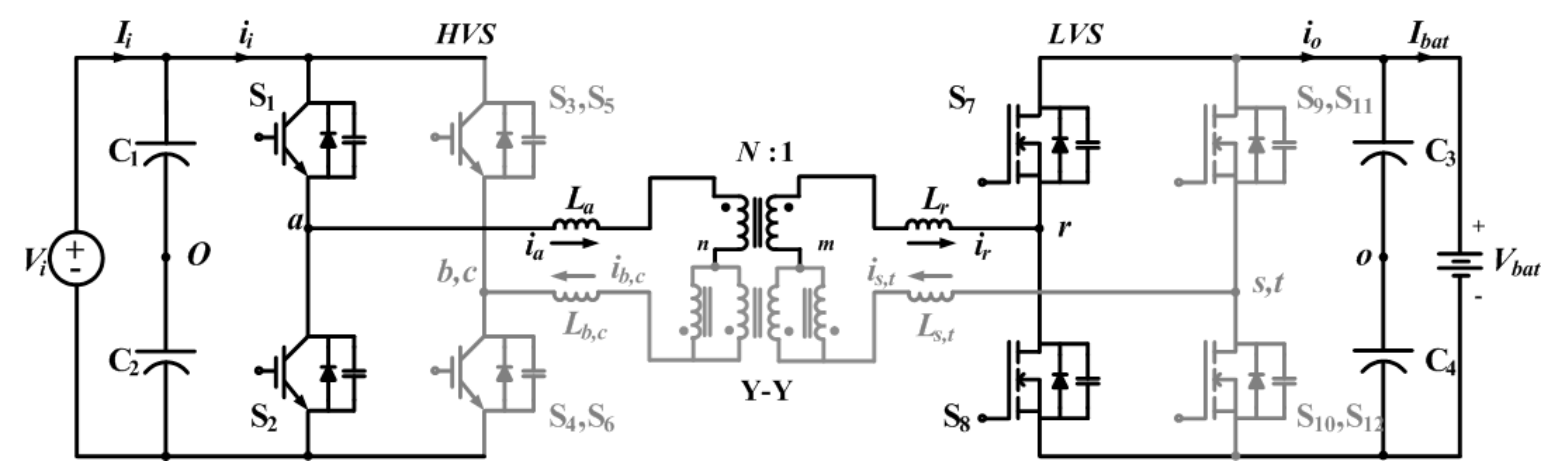

Figure 3. The equivalent circuit with trapezoidal modulation.

Due to parallel operation, voltage and current in the primary side of the transformer have the following relationship:

$$
\begin{gathered}
i_{b}=i_{c}=-0.5 i_{a} \\
V_{b n}=V_{c n}=-0.5 V_{a n}=-V_{i} / 3
\end{gathered}
$$

Thus $P_{T}$ could be simple controlled by two variables $\delta_{T}$ and $D_{1}$. Once the variable $\delta_{T}$ is decided, the duty cycle $D_{1}$ can be obtained as shown in Equation (10):

$$
D_{1}=\frac{-d \delta_{T}+\sqrt{d^{2} \delta_{T}^{2}+(1-d) V_{i}^{2} \cdot\left(d \delta_{T}^{2} V_{i}^{2}+2 \pi \omega L_{e q T} P_{T}\right)}}{1-d}
$$

\section{Hybrid Modulation Design}

In this paper, a hybrid modulating strategy was proposed to allow the converter to be able to autonomously switch between phase-shift and trapezoidal modes according to output current. The turning point for mode transition is pre-determined based on efficiency analysis, which includes device loss and magnetic loss. The former part consists of both conduction and switching losses. The latter one is estimated based on the datasheet of core material. Table 1 shows the circuit parameters used in this paper. The primary-side and secondary-side switches are IGBTs (IXGK60N60BsD1, $600 \mathrm{~V}$, 75 A, IXYS Co., Ltd., Milpitas, CA, USA) and MOSFETs (IXFK120N20P, 200 V, 120 A, IXYS Co., Ltd., Milpitas, CA, USA), respectively. 
Table 1. Circuit parameters.

\begin{tabular}{cccc}
\hline Parameter & Name & Value & Unit \\
\hline$P_{\text {rated }}$ & Rated power & 1.2 & $\mathrm{~kW}$ \\
$f_{s}$ & Switching frequency & 20 & $\mathrm{kHz}$ \\
$V_{i}$ & Input voltage & 350 & Volt \\
$V_{\text {bat }}$ & Output voltage & $42-58.4$ & Volt \\
$C_{\text {snubber }}$ & Snubber capacitors & 1.0 & $\mathrm{nF}$ \\
$L_{a} L_{b} L_{c}$ & HVS auxiliary inductors & 215 & $\mu \mathrm{H}$ \\
$L_{r} L_{s} L_{t}$ & LVS auxiliary inductors & 6 & $\mu \mathrm{H}$ \\
$L_{\text {leakage }}$ & Leakage inductance & 65 & $\mu \mathrm{H}$ \\
$N$ & Turn ratio & 6 & - \\
$R_{p}$ & Primary-side winding resistance of the transformor & 265 & $\mathrm{~m} \Omega$ \\
$R_{S}$ & Secondary-side winding resistance of the transformor & 102 & $\mathrm{~m} \Omega$ \\
$R_{d s}$ & Conductor Resistance of secondary-side switches & 22 & $\mathrm{~m} \Omega$ \\
\hline
\end{tabular}

\subsection{Loss and Efficiency}

For EV application, the charging operation with adjustable charging current according to the operator is the main focus. That is why we design the converter for high efficiency from light load to heavy load. The power flow of the proposed DAB circuit can be controlled between the primary and secondary sides, so the theoretical analysis has addressed dual operation for both charging and discharging behavior. Figure 4 shows phase-shifted angle and duty ratio with respect to output current for both modulating modes, which were calculated by adjusting phase-shifted angle. Based on the modulation parameters in Figure 4, converter loss and its efficiency can be derived.

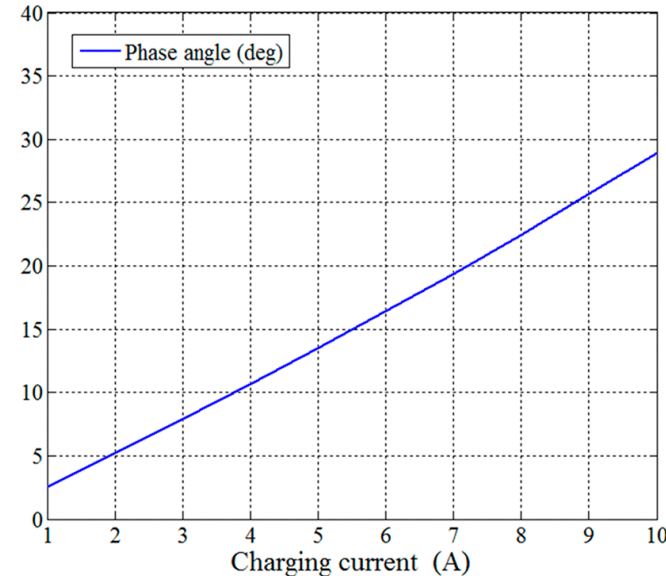

(a)

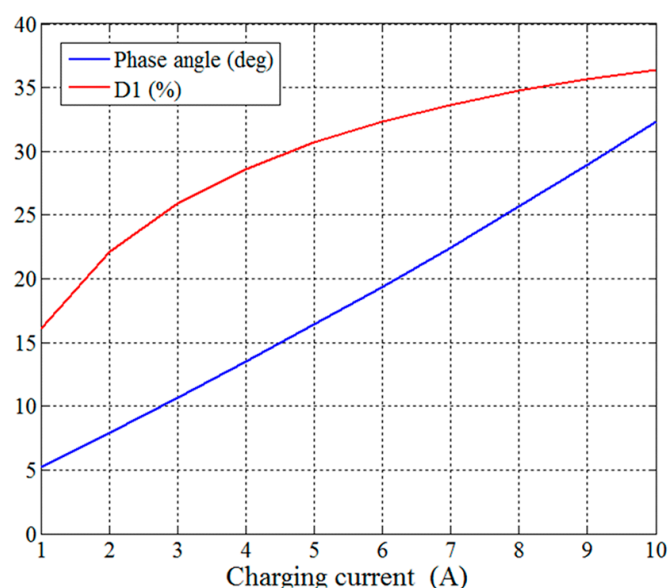

(b)

Figure 4. Modulation parameters with respect to current. (a) Phase-shifted modulation; (b) Trapezoidal modulation.

The 50\% duty ratio makes phase-shifted modulation less loss in high current operation in Figure 5a. However, the phase-shifted modulation suffers from high switching loss in low current range due to loss of ZVS. On the other hand, the trapezoidal modulation benefits in low current range due to reduced circulating current in Figure 5b, but the conduction loss significantly increases with increasing output current. Therefore, the crossover point of the efficiency curves in Figure $5 \mathrm{~d}$ is located around $2 \mathrm{~A}$, which is a preferred selection of the mode-switching current $I_{\text {mode }}$. Despite the power loss equations and simulation results, we still use the trial-and-error method to locate the crossover point of the efficiency curves and select $2 \mathrm{~A}$ as the mode-switching current $I_{\text {mode }}$ in the experiment. The efficiency curves and the preferred mode-switching current $I_{\text {mode }}$ is measured and verified in the experimental results in a later section. 


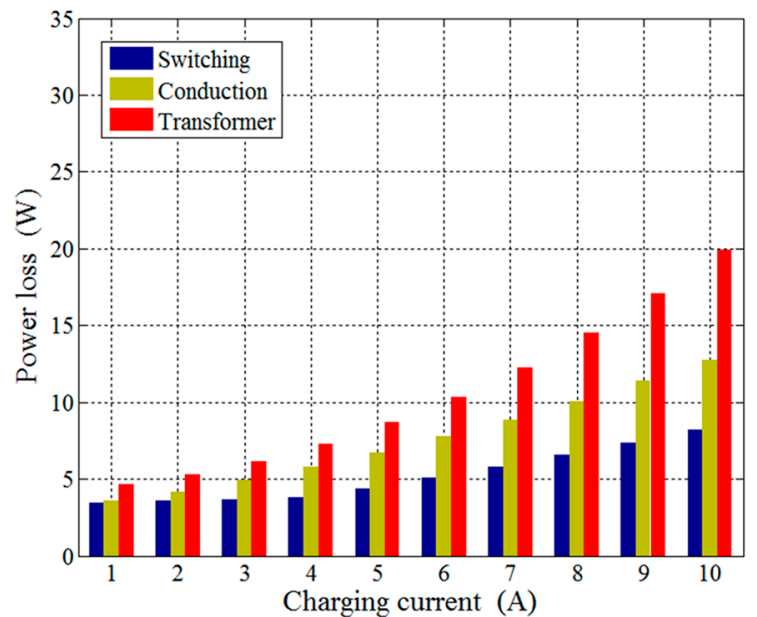

(a)

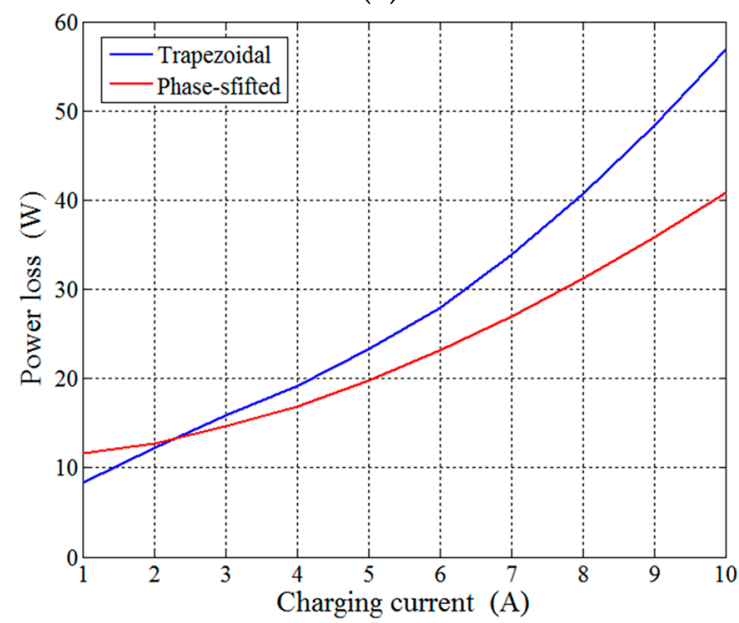

(c)

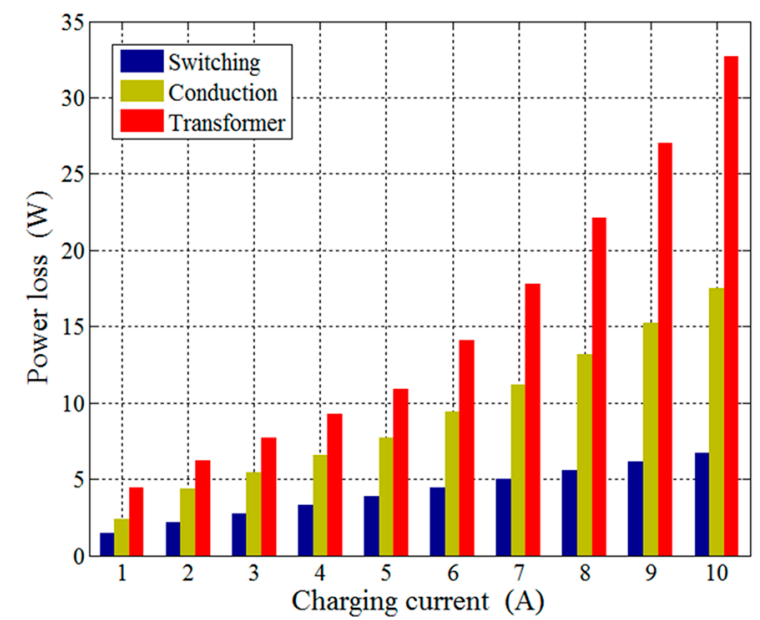

(b)

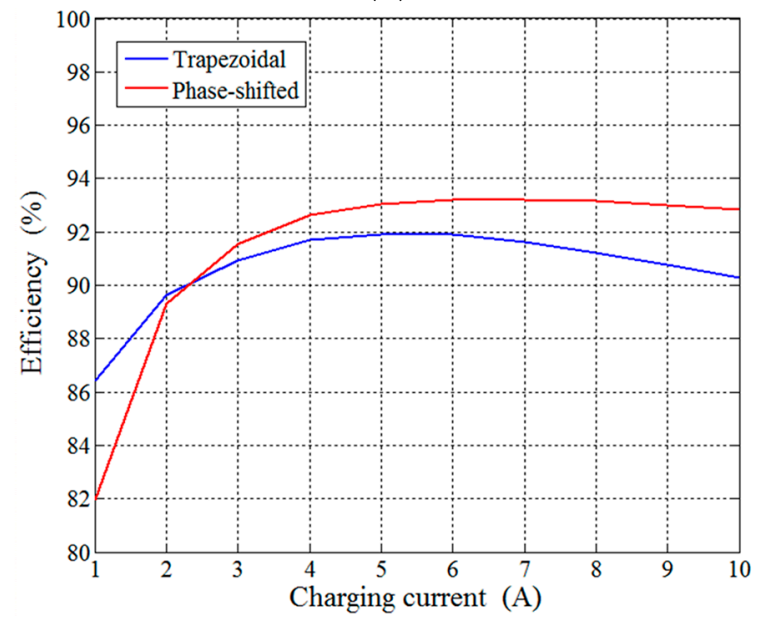

(d)

Figure 5. Simulation result of the power loss and efficiency. (a) Detailed loss with phase-shift; (b) Detailed loss with trapezoidal; (c) The curves of power loss; (d) Efficiency curve.

Because the experimental platform is over-designed for protection, the operation range where the trapezoidal modulation provides better efficiency is limited. If the 600V/40A IGBTs and 200V/50A MOSFETs are chosen, the crossover point will up to $3 \mathrm{~A}$ but the platforms will have higher risk.

\subsection{Control Scheme}

Figure 6a shows the proposed control block diagram, including battery charging scheme and hybrid modulator. The logical switches shown are to explain control flow only. Both constant-current (CC) and constant-voltage (CV) modes are designed in the battery charging algorithm. In the $\mathrm{CC}$ mode, logic switch $S_{C V}$ is set at off-state so that the modulator input is simply determined by current command $I_{\text {comd }}$ only. On the other hand, battery voltage $V_{b a t}$ is required for CV operation. As shown, logic switch $S_{C V}$ is changed to on-state to produce the modified current $\mathrm{I}_{\mathrm{CV}}$ that is added to $I_{\text {comd }}$ for the hybrid modulator.

Based on the pre-determined current turning-point $I_{\text {mode, }}$ a suitable modulation, phase-shifted or trapezoidal mode, is selected to generate a phase-shifted angle and/or duty ratio. As shown, in phase-shifted modulation, the logic switch $S_{P S}$ is turned on to allow a PI controller generating phase angle command $\delta$ according to the current command $I_{\text {comd }}$. On the other hand, duty ratio command $D_{1}$ can be produced by turning on $S_{T A}$ for the trapezoidal mode. The required phase angle $\delta_{T}$ is the phase-shifted angle at current turning-point $I_{\text {mode }}$. Figure $6 \mathrm{~b}$ shows the mode transition of the hybrid 
modulator, where $I_{\text {mode }}$ is set as 2 A. As shown, $\delta$ and $D_{1}$ are controllable variables for the current command larger and less than $2 \mathrm{~A}$, respectively.

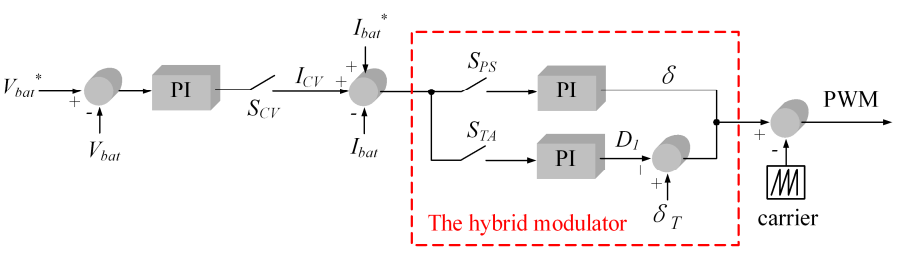

(a)

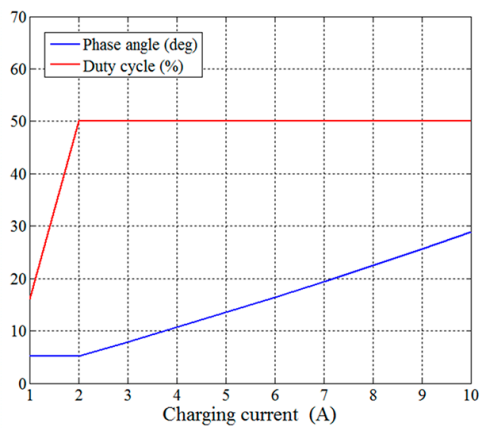

(b)

Figure 6. The control scheme and hybrid modulation. (a) The control scheme of the converter; (b) Phase angle and duty cycle of hybrid modulation.

There are two variables, duty cycle $D_{1}$ and phase angle $\delta_{T}$ in trapezoidal modulation. When switching from phase-shift to trapezoidal modulation, the phase angle $\delta$ generated by phase-shift modulation is sent to trapezoidal modulation as a fixed variable. During the trapezoidal modulation, the phase angle won't be changed by the PI because the $S_{P S}$ in Figure 6a is off. This hybrid modulator design reduces the bouncing problem between modulations.

Figure 7 shows the flowchart of the proposed control scheme. After obtaining a battery charging or discharging command, the converter determines its operation based on battery voltage. In charging case, CC mode is normally chosen and the hybrid modulator determines the modulating strategy according to $I_{\text {mode }}$. At the end of charging, $\mathrm{CV}$ is started instead to decrease charging current. The charging process is ended as the charging current is less than $0.4 \mathrm{~A}$. For discharging requirement, only current command is needed. A low-voltage limitation $42 \mathrm{~V}$ is considered in this case for preventing battery from over-discharging.

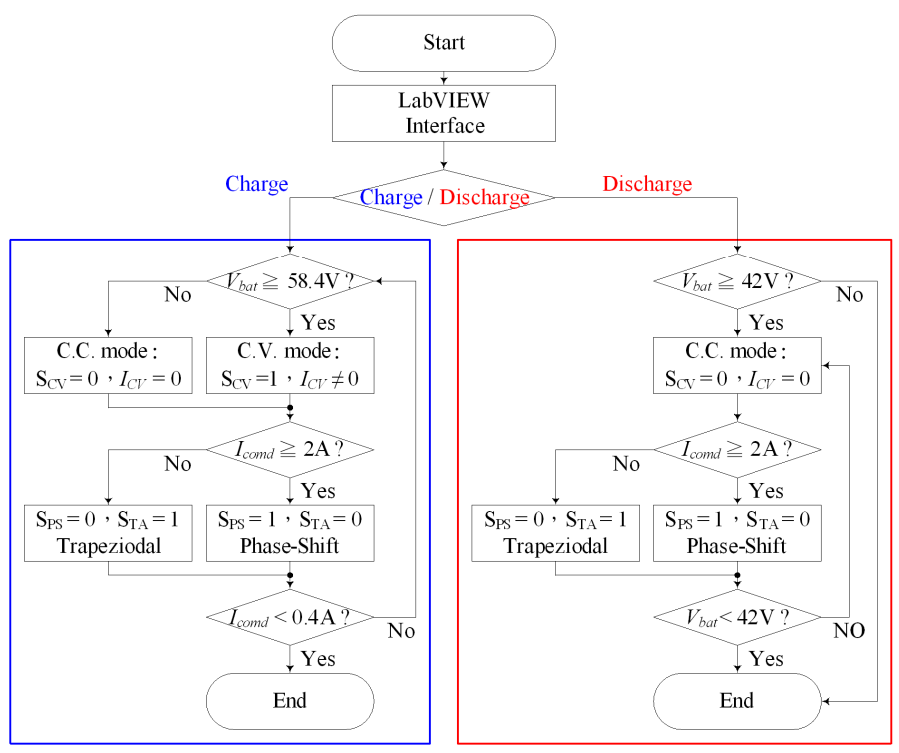

Figure 7. The flowchart of the proposed control scheme. 


\section{Experimental Results}

An experimental prototype is established to measure efficiency of the three-phase DAB converter with the hybrid modulation, and experimental parameters are shown in Table 1 . Considering power rating, voltage rating and over-design for protection, the converter circuit use IGBTs (IXGK60N60BsD1, $600 \mathrm{~V}, 75 \mathrm{~A}$ ) as primary-side switches and MOSFETs (IXFK120N20P, $200 \mathrm{~V}, 120 \mathrm{~A}$ ) as secondary-side switches. A DC power supply is applied to theprimary side while the $\mathrm{LiFePO}_{4}$ battery (TY-D 20-48, $20 \mathrm{AH}$, Ty Dynamic Co., Ltd., New Taipei City, Taiwan) is applied to the secondary side. A three-phase transformer is composed by three single-phase ferrite-core transformers (ferrite core, EE55-28-21-MB3, New Favor Industry Co., Ltd., Taipei, Taiwan). The leakage inductance of the transformer is referred to the high-voltage side. The control strategy of the converter is accomplished via usage of a digital signal processors (DSPs, TMS320C28335, Texas Instruments, Dallas, TX, USA).

\subsection{Steady State}

Figure 8a shows $V_{a n}, V_{r m}, i_{a}$ waveforms when the converter is operated at $I_{B}{ }^{*}=1 \mathrm{~A}$. Obviously, trapezoidal modulation is enabled with parameters $D_{1}=23.5 \%(11.75 \mu \mathrm{s}), D_{2}=25.86 \%(11.75 \mu \mathrm{s})$ and $\delta_{T}=5.2^{\circ}(0.72 \mu \mathrm{s})$. Note that the transformer current $i_{a}$ is approximately equal to $0.1 \mathrm{~A}$ due to dead time. Figure $8 \mathrm{~b}$ shows key waveforms in phase-shifted modulation at $I_{B}{ }^{*}=10 \mathrm{~A}$, in which the phase angle $\delta$ is $30^{\circ}$. Figure $8 \mathrm{c}$ shows the waveforms also in phase-shifted modulation but with $I_{B}{ }^{*}=-10 \mathrm{~A}$ discharging current.

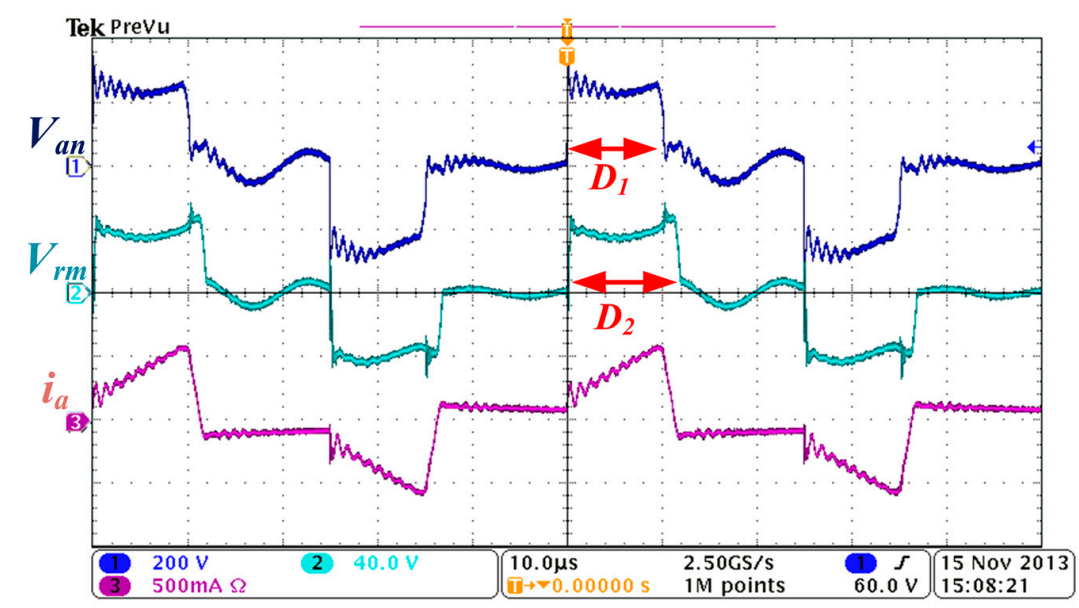

(a)

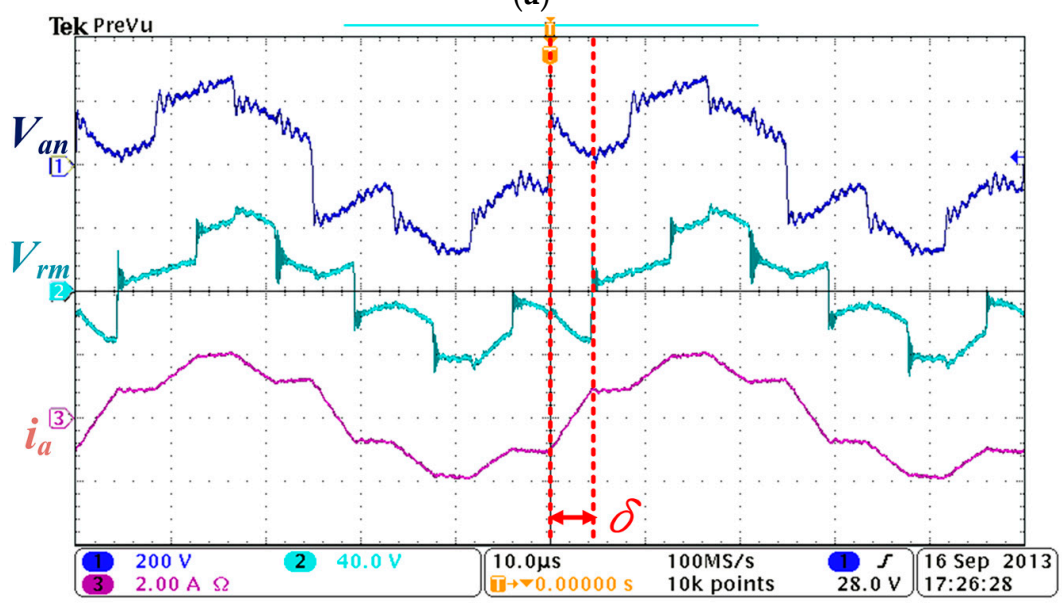

(b)

Figure 8. Cont. 


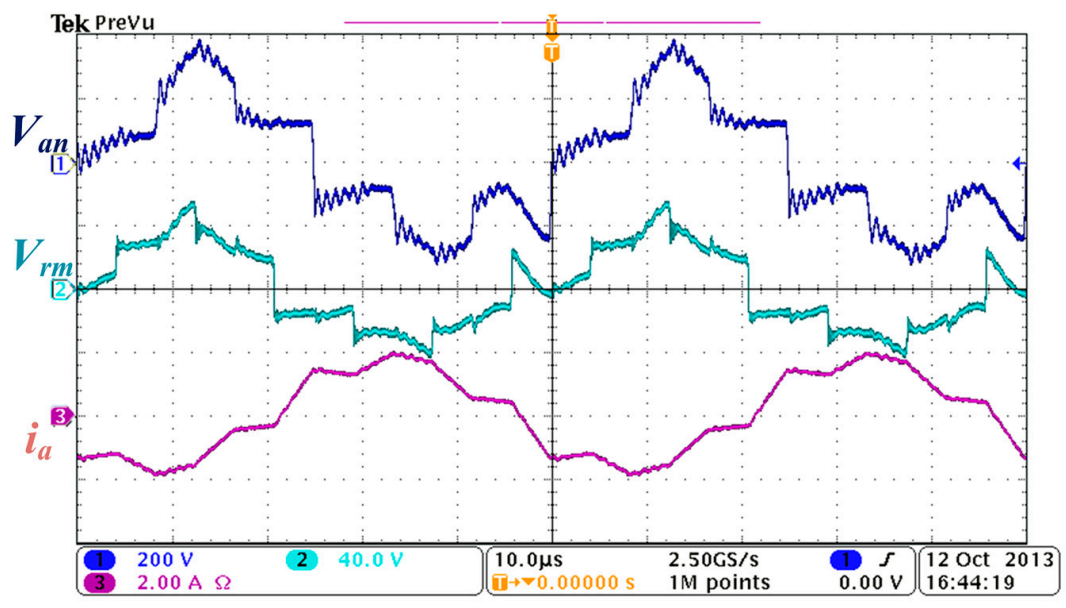

(c)

Figure 8. Steady-state waveforms. (a) Trapezoidal modulation with 1 A charging current; (b) Phase-shifted modulation with 10 A charging current; (c) Phase-shifted modulation with 10 A discharging current.

\subsection{Transient Behaviour}

Figure 9a illustrates the transient waveform when the charging current command $I_{b a t}{ }^{*}$ increases from 1 to $4 \mathrm{~A}$. As expected, the modulation is successfully switched from trapezoidal mode to phase-shifted mode. Figure $9 \mathrm{~b}$ shows the transient behavior when the charging current command $I_{\text {bat }}{ }^{*}$ is increased from 0 to 4,6 and $8 \mathrm{~A}$, respectively. As shown, the charging current $I_{b a t}$ can is able to follow the current command $I_{\text {bat }}{ }^{*}$.

In normal operation, the current command $I_{\text {comd }}$ is tuned slowly in constant-voltage mode, so the PI controller in the hybrid modulator can be designed for fast-tracking ability with hard-to-notice overshoot transient. Since the transient experiments are extreme case of current-command- $I_{\text {comd }}$ adjustment, the current spikes in Figure $9 \mathrm{~b}$ actually is the overshoot expressed in terms of $2 \mathrm{~s} / \mathrm{div}$, which is induced by the fast-tracking PI controller.

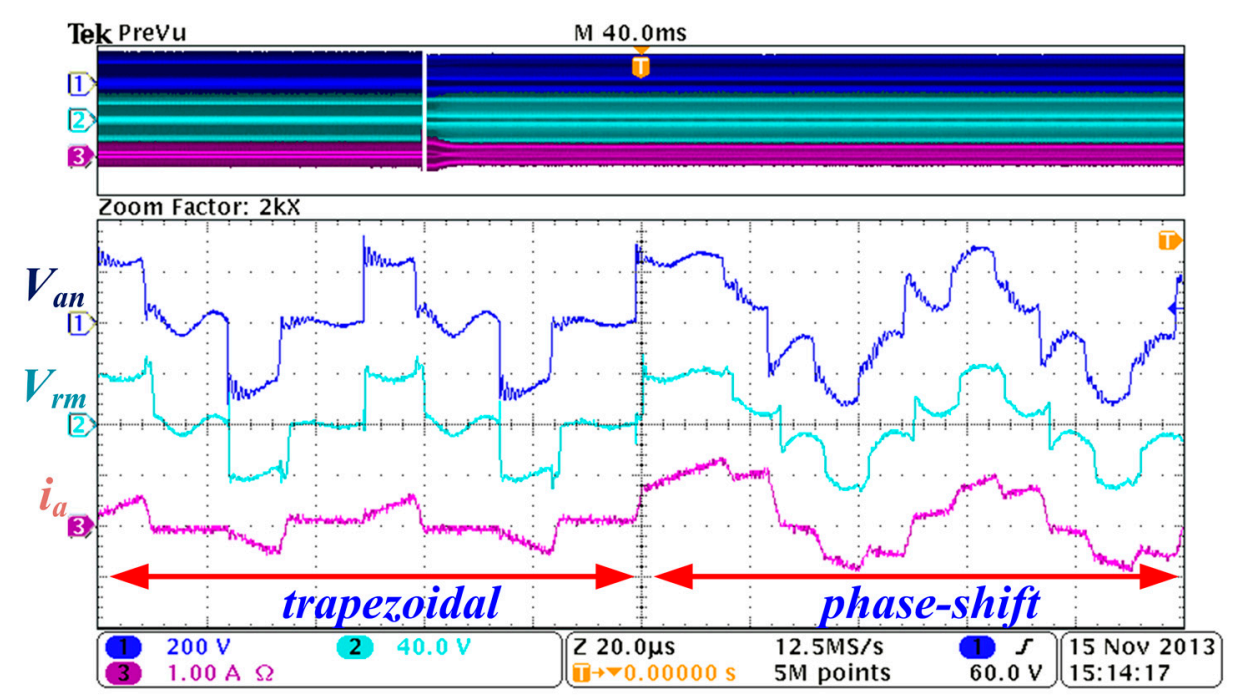

(a)

Figure 9. Cont. 


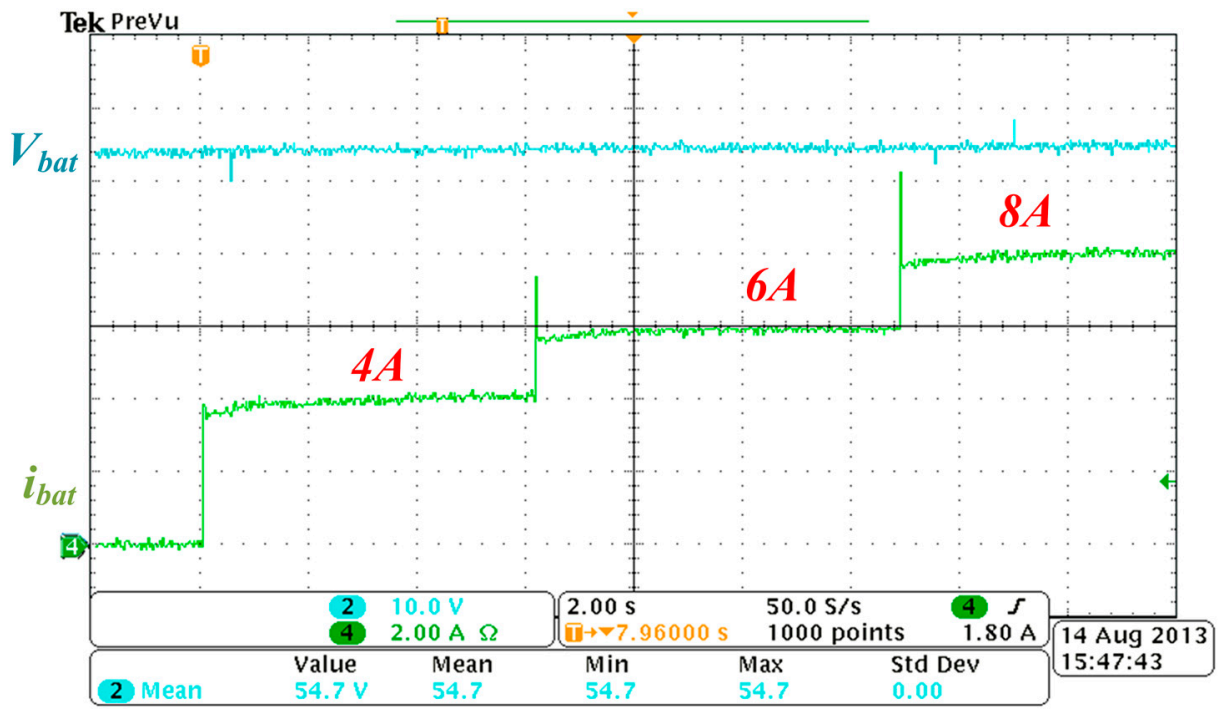

(b)

Figure 9. Transient waveforms. (a) Waveforms when the modulation switches; (b) Waveforms when charging current changes.

\subsection{Operation}

Figure 10 shows battery voltage $V_{b a t}$ and battery current when the operation of the converter changes from CC mode to CV mode. The converter runs in CC mode at $I_{b a t}{ }^{*}=10 \mathrm{~A}$ during $t_{0}-t_{1}$ period, which is modulated by the phase-shifted scheme. When the battery voltage is equal to $58.4 \mathrm{~V}$ at $t_{1}$, the charging mode switches to $\mathrm{CV}$ mode. During the $\mathrm{CV}$ mode, the converter still operates in phase-shifted modulation during $t_{1}-t_{2}$ period since the charging current $I_{b a t}$ is larger than $I_{\text {mode }}=2 \mathrm{~A}$. When $I_{b a t}$ is less than $2 \mathrm{~A}$, the converter changes its modulation to the trapezoidal mode during the $t_{2}-t_{3}$ period. After $I_{b a t}$ is smaller than $0.4 \mathrm{~A}$ at $t_{3}$, the battery charging is terminated.

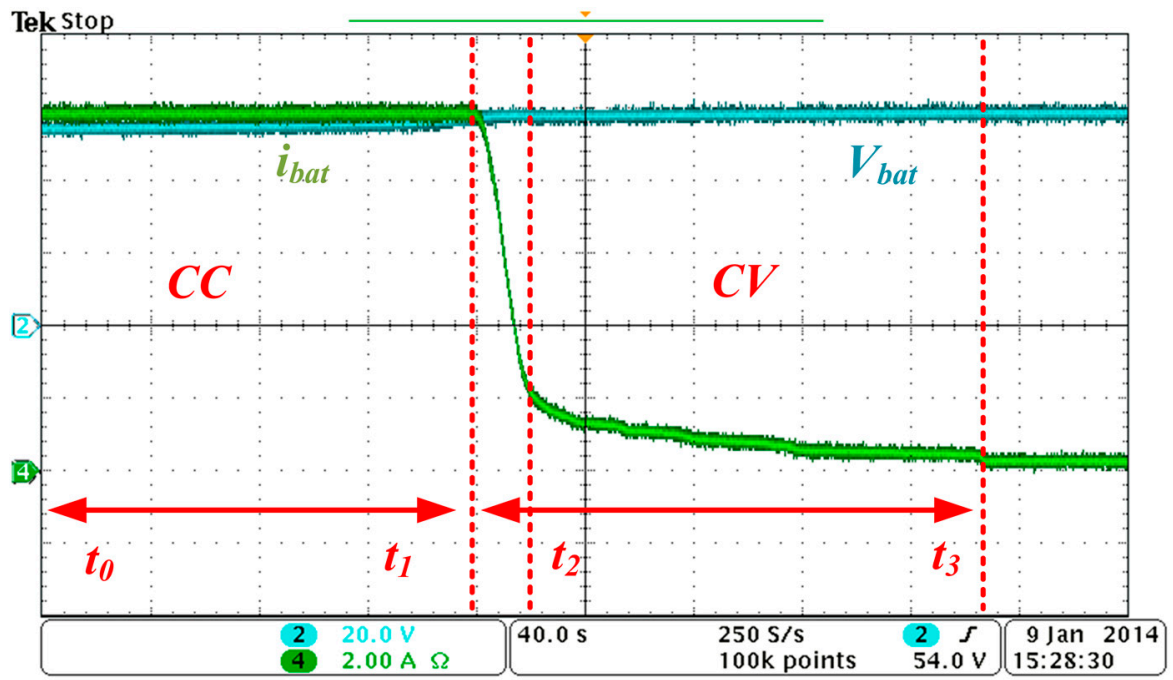

Figure 10. The CC/CV waveform.

\subsection{Efficiency}

The measured efficiency curve is shown in Figure 11a. The efficiency is improved as the charging current less than 2 A. For example, the efficiency is increased from $83.04 \%$ to $88.66 \%$ at $I_{\text {mode }}=1 \mathrm{~A}$. 
Figure 11b gives detailed measurements of the power loss in phase-shifted mode and the result in the trapezoidal mode for light load condition. Label on 1 and on 2 stand for the turn-on loss of primary- and secondary-side switches, respectively; label off 1 and off 2 stand for the turn-off loss of primary- and secondary-side switches, respectively; the label cond 1 and cond 2 stand for the conduction loss of primary- and secondary-side switches, respectively; label Tr stands for the transformer loss. Transformer loss occupies over $60 \%$ loss, which might be improved by using low core loss material. This results verifies the availability of hybrid method.

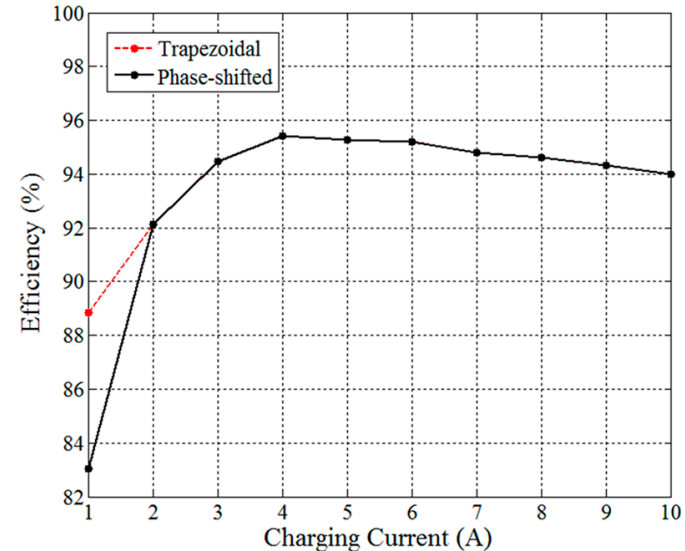

(a)

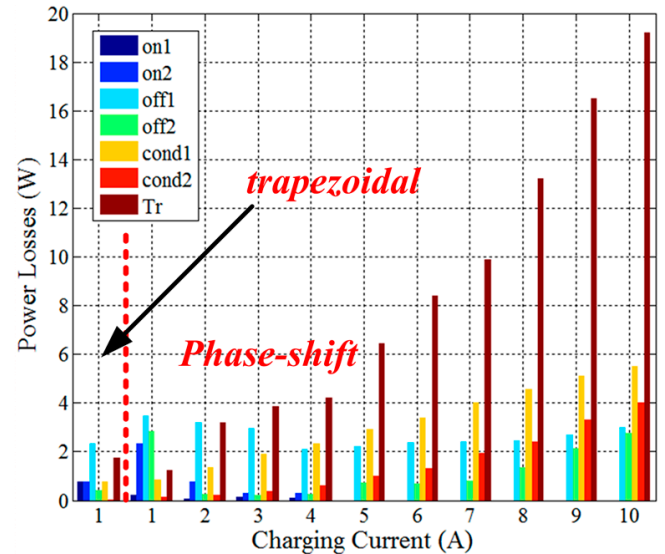

(b)

Figure 11. Analysis of efficiency and loss. (a) Measured efficiency of the converter with hybrid modulation; (b) Histogram of the power loss.

Figure 12 shows the charging and discharging efficiency curves with phase-shift modulation, where the overall efficiency during discharging operation is $0.5 \%$ to $1 \%$ lower than the charging efficiency. The voltage gain $d$ becomes reciprocal and decreases when discharging from low voltage to high voltage. According to power transfer Equations (1) and (2), the phase-shift angle $\delta$ increases based on the decreased voltage gain $d$ while maintaining the same transfer power, so the peaks of transfer three phase current causally raises which aggravate the transfer loss and reduce the efficiency slightly.

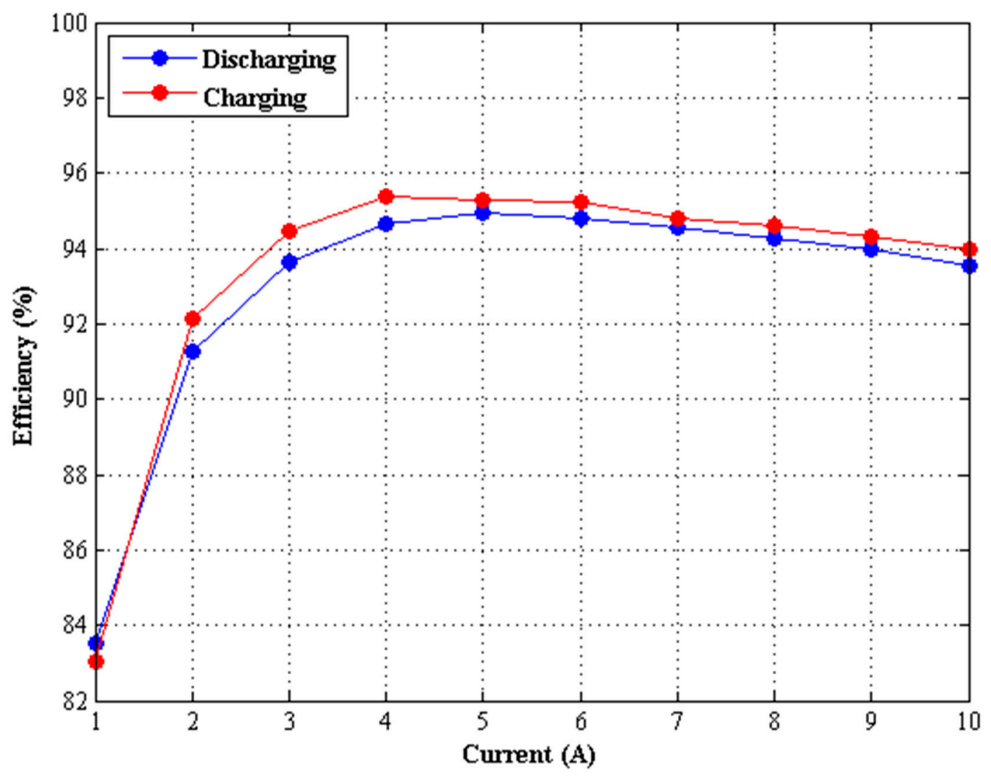

Figure 12. Measured charging and discharging efficiency. 


\section{Conclusions}

This paper proposes and realizes a hybrid modulation strategy designed for the bidirectional three-phase dual-active bridge ( $3 \Phi \mathrm{DAB}) \mathrm{DC}$ converter designed for EV charger applications. The hybrid modulation, which consists of the phase-shifted and trapezoidal modulation, covers the every power loading condition with the most efficient method and increases the over-all efficiency. The proposed control strategy applies two different modulations in on-time operation according to the magnitude of the charging/discharging current. A corresponding suggested control flowchart for hybrid modulation is also provided. A lab-scaled converter prototype with a $48 \mathrm{~V} / 20 \mathrm{Ah} \mathrm{LiFePO}_{4}$ battery is established to validate the feasibility and the effectiveness of the proposed modulation method. The results show that efficiency can be increased under light load conditions.

Acknowledgments: This work is funded by the Ministry of Science and Technology of Taiwan under grant 104-2221-E-110-037-.

Author Contributions: Fu-Ming Ni, Yen-Ching Wang and Tzung-Lin Lee conceived and designed the experiments; Fu-Ming Ni performed the experiments; Fu-Ming Ni and Yen-Ching Wang analyzed the data; Tzung-Lin Lee contributed reagents/materials/analysis tools; Yen-Ching Wang wrote the paper.

Conflicts of Interest: The authors declare no conflict of interest.

\section{References}

1. Inoue, S.; Akagi, H. A bidirectional DC-DC converter for an energy storage system with galvanic isolation. IEEE Trans. Power Electron. 2007, 22, 2299-2306. [CrossRef]

2. Cvetkovic, I.; Thacker, T.; Dong, D.; Francis, G.; Podosinov, V.; Boroyevich, D.; Wang, F.; Burgos, R.; Skutt, G.; Lesko, J. Future home uninterruptable renewable energy system with vehicle-to-grid technology. In Proceedings of the Energy Conversion Congress and Exposition, San Jose, CA, USA, 20-24 September 2009; pp. 2675-2681.

3. Erb, D.C.; Onar, O.C.; Khaligh, A. Bi-directional charging topologies for plug-in hybrid electric vehicles. In Proceedings of the IEEE Applied Power Electronics Conference and Exposition, Palm Springs, CA, USA, 21-25 February 2010; pp. 2066-2072.

4. Yilmaz, M.; Krein, P.T. Review of battery charger topologies, charging power levels, and infrastructure for plug-in electric and hybrid vehicles. IEEE Trans. Power Electron. 2013, 28, 2151-2169. [CrossRef]

5. Tuttle, D.P.; Baldick, R. The evolution of plug-in electric vehicle-grid interactions. IEEE Trans. Smart Grid 2012, 3, 500-505. [CrossRef]

6. Tuttle, D.P.; Fares, R.L.; Baldick, R.; Webber, M.E. Plug-in vehicle to home (V2H) duration and power output capability. In Proceedings of the Transportation Electrification Conference and Expo (ITEC), Detroit, MI, USA, 16-19 June2013; pp. 1-7.

7. Krismer, F.; Round, S.; Kolar, J.W. Performance optimization of a high current dual active bridge with a wide operating voltage range. In Proceedings of the 37th IEEE Power Electronics Specialists Conference, Jeju, Korea, 18-22 June 2006; pp. 1-7.

8. Yamamoto, K.; Hiraki, E.; Tanaka, T.; Nakaoka, M.; Mishima, T. Bidirectional DC-DC converter with full-bridge/push-pull circuit for automobile electric power systems. In Proceedings of the Power Electronics Specilists Conference (PESC), Jeju, Korea, 18-22 June 2006.

9. Kim, M.; Rosekeit, M.; Sul, S.K.; De Doncker, R.W. A dual-phase-shift control strategy for dual-active-bridge DC-DC converter in wide voltage range. In Proceedings of the International Conference on Power Electronics-ECCE Asia, Jeju, Korea, 30 May-3 June 2011.

10. Oggier, G.G.; García, G.O.; Oliva, A.R. Modulation strategy to operate the dual active bridge DC-DC converter under soft switching in whole operating range. IEEE Trans. Power Electron. 2011, 26, 1228-1236. [CrossRef]

11. Zhou, H.; Khambadkone, A.M. Hybrid modulation for dual-active-bridge bidirectional converter with extended power range for ultracapacitor application. IEEE Trans. Ind. Appl. 2008, 45, 1434-1442. [CrossRef]

12. Schibli, N. Symmetrical Multilevel Converters with Two Quadrant DC-DC Feeding. Ph.D. Thesis, Ecole Polytechnique Federale de Lausanne, Industrial Electronics laboratory, Lausanne, Switzerland, 2000. 
13. Bai, H.; Mi, C. Eliminate reactive power and increase system efficiency of isolated bidirectional dual-active-bridge DC-DC converters using novel dual-phase-shift control. IEEE Trans. Power Electron. 2008, 23, 2905-2914. [CrossRef]

14. Oliveria, D.S.; Barbi, I. A three-phase ZVS PWM DC/DC converter with asymmetrical duty cycle for high power applications. IEEE Trans. Power Electron. 2005, 20, 354-360. [CrossRef]

15. Krismer, F. Modeling and Optimization of Bidirectional Dual Active Bridge DC-DC Converter Topologies. Ph.D. Thesis, ETH Zurich, Zurich, Switzerland, 2010.

16. Kim, H.; Yoon, C.; Choi, S. A three-phase zero-voltage and zero-current switching DC-DC converter for fuel cell applications. IEEE Trans. Power Electron. 2010, 25, 391-398.

17. Wang, Z.; Li, H. A Soft switching three-phase current-fed bidirectional DC-DC converter with high efficiency over a wide input voltage range. IEEE Trans. Power Electron. 2012, 27, 669-684. [CrossRef]

18. De Doncker, R.W.; Divan, D.M.; Kheraluwala, M.H. A three-phase soft-switching high-power-density DC/DC converter for high-power applications. IEEE Trans. Ind. Appl. 1991, 27, 63-73. [CrossRef]

19. Van Hoek, H.; Neubert, M.; Krober, A.; De Doncker, R.W. Enhanced modulation strategy for a three-phase dual active bridge- boosting efficiency of an electric vehicle converter. IEEE Trans. Power Electron. 2013, 28, 5499-5507. [CrossRef]

20. Van Hoek, H.; Neubert, M.; Krober, A.; De Doncker, R.W. Comparison of a single-phase and a three-phase dual active bridge with low-voltage, high-current output. In Proceedings of the 2012 International Conference on Renewable Energy Research and Applications (ICRERA), Nagasaki, Japan, 11-14 November 2012; pp. 1-6.

21. Ni, F.-M.; Lee, T.-L. Implementation of a bidirectional three-phase dual-active-bridge DC converter for electric vehicle applications. In Proceedings of the International Future Energy Electronics Conference, Tainan, Taiwan, 3-6 November 2013.

22. Jain, A.; Ayyanar, R. PWM control of dual active bridge: Comprehensive analysis and experimental verification. IEEE Trans. Power Electron 2011, 26, 1215-1227. [CrossRef]

(C) 2016 by the authors; licensee MDPI, Basel, Switzerland. This article is an open access article distributed under the terms and conditions of the Creative Commons Attribution (CC-BY) license (http://creativecommons.org/licenses/by/4.0/). 